
\title{
Research S Surate \\ Numerical Modelling of Carrier Transport in Organic Field Effect Transistors
}

\section{Salma A. Hussien}

The British University in Egypt

Sameh 0. Abdullatif ( $\nabla$ Sameh.osama@bue.edu.eg)

The British University in Egypt https://orcid.org/0000-0001-8677-9497

\section{Research Article}

Keywords: Bottom-gate transistors, Carrier transport numerical modelling, Field Effect Transistors, Organic semiconductors.

Posted Date: January 4th, 2022

DOI: https://doi.org/10.21203/rs.3.rs-832025/v1

License: (1) This work is licensed under a Creative Commons Attribution 4.0 International License. Read Full License 


\title{
Numerical Modelling of Carrier Transport in Organic Field Effect Transistors
}

\author{
Salma A. Hussien ${ }^{1}$ and Sameh O. Abdullatif ${ }^{*}$ \\ ${ }^{1}$ FabLab in the Centre for Emerging Learning Technologies (CELT), Electrical Engineering Department, Faculty of Engineering,
} The British University in Egypt (BUE), El-Sherouk 11837, Cairo, Egypt

This paper has not been submitted or presented elsewhere previously

*Corresponding Author: Sameh O. Abdullatif

Address: FabLab in the Center for Emerging Learning Technologies (CELT), Electrical Engineering Department, Faculty of Engineering, The British University in Egypt (BUE), El-Sherouk 11837, Cairo, Egypt

Email: Sameh.osama@bue.edu.eg

Tel: +20 1222194077

\begin{abstract}
Organic field effect transistors (OFETs), used in the fabrication of nano-sensors, are one of the most promising devices in the field of organic electronics, because of their light weight, flexible and low fabrication cost. However, the optimization of such OFETs is still in an early stage due to the very limited analytical as well as numerical models presented in the literature. This research presses to demonstrate a numerical carrier transport model based on finite element method (FEM), to investigate the I-V characteristic of OFETs. Two various organic semiconductor materials have been included in the study, polyaniline and pentacene, where a micro-scale as well as a nano-scale models have been presented. OFETs have been studied in terms of channel length, dielectric thickness, and doping level impact. We nominated the threshold voltage, the on/off current ratio, the sub threshold swing, and the field effect mobility's as the main output evaluating parameters. The numerical model has shown the criticality of the doping effect on tuning the device flowing drain current, to exceed $300 \mu \mathrm{A}$ saturation current, along with threshold voltage of $-0.1 \mathrm{~V}$ under a channel length of $30 \mathrm{~nm}$. Additionally, the study highlights the effectiveness of the polyaniline over pentacene as nano-channel length OFET, due to the boosted conductivity of polyaniline with respect to pentacene.
\end{abstract}

Keywords: Bottom-gate transistors, Carrier transport numerical modelling, Field Effect Transistors, Organic semiconductors.

\section{Declarations}

Funding: The authors would like to acknowledge the support and contribution of the STDF in this work. As part of the STDF Project ID\#33502.

Conflicts of interest/Competing interests: The Authors declare that there is no conflict of interest.

Availability of data and material: The data that support the findings of this study are available as following: https://www.mathworks.com/matlabcentral/fileexchange/97844-ofets

Any other data that support the findings of this study are available from the corresponding author upon reasonable request.

Code availability: Not applicable' for that section

Authors' contributions: All authors have contributed equally.

Ethics approval: Not applicable' for that section

Consent to participate: All authors confirm the participation in this paper.

Consent for publication: All authors accept the publication rules applied by the journal. 


\section{Introduction}

At recent years, the interest with low-power consumption sensors increases, where massive studies focus on cost-effective devices for sensing different environmental as well as medical parameters glows up [15]. Different electronic organic-based devices (ex: light-emitting diodes and transistors) have been studied and researched extensively seeking for lower weight, sustainability, flexibility, and lower energy consumption [6, 7]. Among these devices, organic field effect transistor (OFET) has been utilized in flexible sensor's fabrication [7]. OFET showed potential in wide range of sensing applications, including but not limited to light sensors [8], chemical sensors [9, 10], pressure sensors [11] and biosensors [12-14].

The term "Organic Semiconductors" (OSCs) is not new. In early of twenty-first century, the first studies of organic semiconductors were investigated [15]. Since 1970s the development of organic semiconductors was propelled by the successful synthesis and the doping control of conjugated polymers [16]. The interest of organic semiconductors is increasing these days, because of the low production cost, low fabrication temperature, availability, and mechanical flexibility [17]. These features distinguish OSCs from the traditional inorganic semiconductors [18].

Organic semiconductors seem to be different from the inorganic semiconductors because organic molecules produce solid that resulted from Van-der Waals interactions, whereas inorganic solids created by covalent bonded molecules. That results a weaker intermolecular bonding [19]. However organic semiconductors have lower mobility compared to inorganic materials, where mobility of organic materials can reach $15 \mathrm{~cm}^{2} / \mathrm{V} . \mathrm{s}$ [20].

Organic semiconductors are divided into two main classifications: low molecular weight compounds and polymers. Both categories have a common property which is the presence of a conjugated system of $\pi$ bond formed from P-orbitals of carbon atoms of trigonal hybridization [15, 21, 22]. Following the literature, polyaniline (PANI), pentacene, poly (3- hexylthiophene) (P3HT), poly (3-alkylthiophene) (P3AT), and poly (3-octylthiophene) (P3OT) are the most commonly used OSCs in OFET technology [23].

OFETs have several architectures that depending on the placement sequence of the active layer (organic semiconductor) and the electrodes of source, drain and gate. The possible four structures of OFETs are bottom-gate top-contacts (BG/TC), bottom-gate bottom-contacts (BG/BC), top-gate bottom-contacts (TG/BC) and top-gate top-contacts (TG/TC) [7]. The arrangements of the active region with respect to the electrodes have a great impact on the performance of the device, where every architecture showed its pros and cons. For example, the bottom-contacts devices are preferable for manufacturing because source and drain electrodes can be patterned in the channel dimensions on nanoscale using photolithography techniques without any destruction for the active layer [24]. Alternatively, top-contact's manufacturing is a challenging process, as the deposition process could damage the organic semiconductor, where metal atoms can diffuse into the active layer [25]. On the other hand, the field effect mobility's of top-contacts are measured to be higher than other structures. This is attributed to the lower resistance of top-contacts than bottom-contacts resistance [26]. Moreover, the placement of the gate electrodes influences the device performance. Specifically, bottom-gate bottom-contacts architectures are chosen for the quick screening of new active layer or testing new methods for deposition. The easy of fabrication promotes BG/BCls usage in the literature $[27,28]$.

OFETs, as three terminal devices shown in figure 1, are constructed using an organic semiconductor layer, dielectric layer, and metal electrodes. Semiconductor layer is known as the active layer [28]. This layer provides channel, and it can be deposited on dielectric layer (in case of bottom-gate structures discussed in this paper). The dielectric layer is used to induce the charges through active layer which generated from applied gate voltage across dielectriclsemiconductor interface. The dielectric layer can be organic (such as poly (methyl-methacrylate) (PMMA), and poly(4-vinylphenol) (PVP)) or inorganic (such as $\mathrm{SiO}_{2}$ and $\mathrm{AlO}_{3}$ ) materials [23]. In OFETs, gate electrodes are fabricated from metal or conducting 
polymer [21]. While source and drain electrodes are commonly fabricated from gold or silver [28]. Substrates in OFETs are used for mechanical support, with no impact on the device's operation (ex: OFET over plastic and paper substrates [29, 30]). In terms of carrier transport, p-type OFETs are the most commonly used OFET, as the reported hole mobility's in OSCs usually exceed that for electrons [31]. This reflects on the overall OFET performance, specially the on/off current ratio as reported in [32].

Concerning the carrier transport modelling in OFETs, previous attempts were demonstrated in the literature. The work in [33] performed an analytical model to both top and bottom-contacts structures. A 2D model using ATLAS simulator was developed to characterize both structures. The obtain field effect mobility for the bottom-contact and top-contact were 0.0019 and $0.129 \mathrm{~cm}^{2} / \mathrm{Vs}$, respectively. Author in [34] investigated a numerical model for the four different structures of the organic field effect transistors which used for the predication of the I-V characteristic curves for the fabricated transistors. The fundamental parameters used where the physical parameters of the devices, such as channel length and width, the channel doping, and the resistance of contacts. Another attempt towards the bottom-gate topcontact model was simulated in [35]. The simulation was performed using Silvaco [35]. They used DNTT-based (p-type OSC) as an active layer for the OFET. The results show that the bendable OFET is working under applied voltage bias VDS of $-1.5 \mathrm{~V}$ and $\mathrm{V}_{\mathrm{GS}}$ of $-3 \mathrm{~V}$ [35]. It is worth to highlight that by surveying the literate, a very few attempts for numerically modelling the OFETs were observed. Additionally, a literature gap in modelling the performance of some commonly used OSCs in fabricated OFETs was detected. One of these famous OSCs is polyaniline [36-38], where we could not find any related numerical model for OFET with polyaniline as an active layer.

Accordingly, we introduce a finite element based numerical model to study OFET in terms of the I-V characteristic curves. Comsol Multiphysics model was seeded by the electronic material parameters of both pentacene and polyaniline as active OSC materials. With reference to the transistor dimensions, micro and nano-scale OFETs are investigated, to emphasis the influence of the transistor dimension, specifically channel length, on the transistor performance. Additionally, other design parameters, such as dielectric layer thickness and active layer doping level, are explored. For the sake of validation, analytical model introduced in [33] was utilized along with experimental data from the literature.

The paper is organized as follows: in section two, the numerical model is introduced with all the corresponding inputted parameters and dimensions. Moreover, the analytical model used for validation is also described. Section three illustrates all the simulation results implemented in this manuscript. Firstly, the analytical and experimental validation is demonstrated, followed by the two proposed micro and nano-OFET models. Finally, a faire comparison between polyaniline and pentacene is presented.

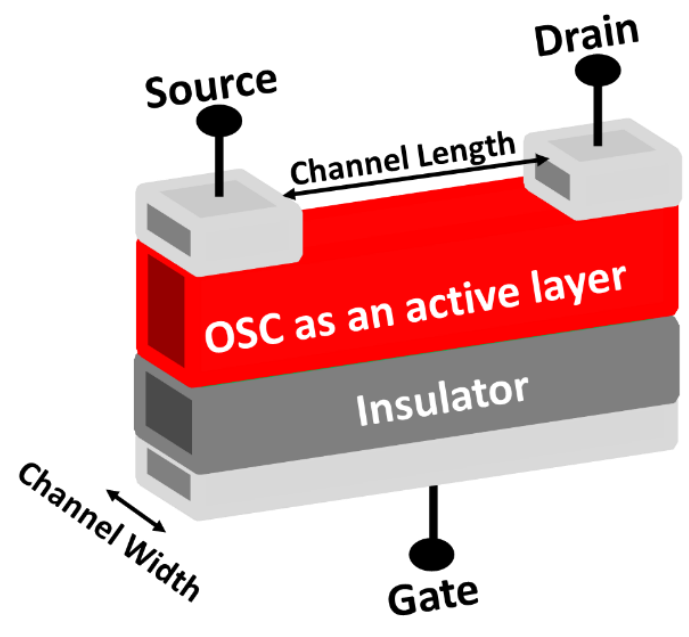


Fig. 1: A demonstrative schematic, not to scale, for the bottom-gate top-contact OFETs simulated using Comsol numerical platform.

\section{Carrier transport simulation model}

A 2D drift diffusion model of organic field effect transistor (OFET) is developed using the semiconductor module in COMSOL Multiphysics 5.5. The bottom-gate top-contacts topology is selected to be implemented through this study, as shown in figure 1 . The drain and source contacts are placed above the active layer (OSC) and the gate contact is below the active layer. Through the current study, two different organic semiconductors are used as the active layer for the simulated OFET. The selected two organic semiconductors are polyaniline (PANI) and pentacene, where all input electrical parameters are captured from the literature and listed in the table 1 [39-42]. Concerning device dimensions, two different scales have been chosen, the first one is a micro-scale OFET ( $\mu$-OFET) with a channel length of $15 \mu \mathrm{m}$. The second is nano-scale OFET ( $\mathrm{n}-\mathrm{OFET}$ ) with $30 \mathrm{~nm}$ channel length. Table 2 illustrates the dimensions for these two scales where ideal Ohmic contacts for both source and drain are assumed.

For the sake of validation, the proposed numerical model is evaluated with respect to the analytical model previously introduced in [33]. The analytical model is presented for a bottom-gate top-contacts organic field effect transistor, however, the study was limited to pentacene as an active OSC material. The drain current in the linear and saturation regions can be obtained by [33]:

$I_{D S}=\frac{\mu C_{i} \frac{W}{L}\left(V_{G S}-V_{T}\right) V_{D S}}{1+\left[\mu C_{i} \frac{2 R_{L}}{L L_{C}}\left(V_{G S}-V_{T}\right)\right]}$
$I_{D S}=\frac{\mu C_{i} \frac{W}{2 L}\left(1+\lambda V_{D S}\right)\left(V_{G S}-V_{T}\right)^{2}}{1+\frac{\mu C_{i} R y}{L L_{C}}\left(V_{G S}-V_{T}\right)^{2}}$

where $W$ and $L$ are the channel width and channel length, $\mu$ and $C_{i}$ are the field effect mobility for the saturation region and channel capacitance for gate dielectric, $V_{G}, V_{T}$, and $V_{D S}$ are the gate, threshold and drain voltage and $R_{L}, L_{C}$ are apparent vertical-direction resistance and the characteristics length, and $\lambda$ is the channel length modulation coefficient. The expressions for obtaining $R_{y}$ are retrieved from the following formulas [33]:

$R_{s h}=\frac{1}{\mu C_{i}\left(V_{G}-V_{T}\right)}$

$R_{y}=L_{c}^{2} R_{s h}$

Where $R_{s h}$ is a dummy internal parameter used to calculate the vertical resistance $R_{y}$. 
Table 1: Input material parameters for Polyaniline and pentacene as the active layer for OFET under simulation

\begin{tabular}{|c|c|c|c|}
\hline Parameter & Description & Polyaniline & Pentacene \\
\hline $\mathrm{N}_{\mathrm{C}}$ & $\begin{array}{c}\text { Effective DOS, } \\
\text { conduction band }\end{array}$ & $1.04 \times 10^{21} \mathrm{~cm}^{-3}$ & $2 \times 10^{21} \mathrm{~cm}^{-3}$ \\
\hline $\mathrm{N}_{\mathrm{V}}$ & $\begin{array}{c}\text { Effective DOS, valence } \\
\text { band }\end{array}$ & $1.04 \times 10^{21} \mathrm{~cm}^{-3}$ & $1.7 \times 10^{21} \mathrm{~cm}^{-3}$ \\
\hline $\mathrm{E}_{\mathrm{g}}$ & Band gap & $2.25 \mathrm{eV}$ & $1.7 \mathrm{eV}$ \\
\hline$\chi$ & Electron affinity & $2.9 \mathrm{eV}$ & $2.8 \mathrm{eV}$ \\
\hline$\varepsilon$ & Relative permittivity & 4 & 4 \\
\hline$\mu_{n}$ & Electron mobility & $10^{-4} \mathrm{~cm}^{2} \mathrm{~V}^{-1} \mathrm{~s}^{-1}$ & $10^{-5} \mathrm{~cm}^{2} \mathrm{~V}^{-1} \mathrm{~s}^{-1}$ \\
\hline$\mu_{p}$ & Hole mobility & $10^{-2} \mathrm{~cm}^{2} \mathrm{~V}^{-1} \mathrm{~s}^{-1}$ & $0.62 \mathrm{~cm}^{2} \mathrm{~V}^{-1} \mathrm{~s}^{-1}$ \\
\hline$\tau_{n}$ & Electron lifetime & $20 \mathrm{~ns}$ & $9.6 \mathrm{~s}$ \\
\hline$\tau_{p}$ & Hole lifetime & $20 \mathrm{~ns}$ & $0.9 \mu \mathrm{s}$ \\
\hline $\mathrm{N}_{\mathrm{a}}$ & Doping in P-type & $1 \times 10^{16} \mathrm{~cm}^{-3}$ & $1.9 \times 10^{16} \mathrm{~cm}^{-3}$ \\
\hline$\varepsilon$ & $\begin{array}{c}\text { Oxide relative } \\
\text { permittivity }\end{array}$ & 4.5 & 3.9 \\
\hline$\phi$ & $\begin{array}{c}\text { Gate metal work } \\
\text { function }\end{array}$ & $4.5 \mathrm{eV}$ & $5.1 \mathrm{eV}$ \\
\hline
\end{tabular}

Table 2: Nano/micro-scale OFET dimensions used in the proposed COMSOL model.

\begin{tabular}{|c|c|c|}
\hline Dimension scale & Physical parameter & Value \\
\hline \multirow{4}{*}{$\begin{array}{c}\text { Nano-scale } \\
(\mathrm{n}-\text { OFET })\end{array}$} & Channel length & $30(\mathrm{~nm})$ \\
\cline { 2 - 3 } & Thickness of active layer & $30(\mathrm{~nm})$ \\
\cline { 2 - 3 } & Source and drain contacts width & $60(\mathrm{~nm})$ \\
\cline { 2 - 3 } & Source and drain contacts height & $15(\mathrm{~nm})$ \\
\cline { 2 - 3 } & Dielectric layer thickness $\left(\tau_{\mathrm{ox}}\right)$ & $200 \mathrm{~nm}$ \\
\hline \multirow{4}{*}{$\begin{array}{c}\text { Micro-scale } \\
(\mu-O F E T)\end{array}$} & Channel length & $15(\mu \mathrm{m})$ \\
\cline { 2 - 3 } & Thickness of active layer & $60(\mathrm{~nm})$ \\
\cline { 2 - 3 } & Source and drain contacts width & $0.4(\mu \mathrm{m})$ \\
\cline { 2 - 3 } & Source and drain contacts height & $40(\mathrm{~nm})$ \\
\cline { 2 - 3 } & Dielectric layer thickness $\left(\tau_{\mathrm{ox}}\right)$ & $40(\mathrm{~nm})$ \\
\hline
\end{tabular}

\section{Simulation results and discussion}

In this section, all numerical as well as analytical simulation results are illustrated. A comparison between our model results and previous reputed data from the literature is firstly presented for the sake of validation. Secondly, the impact of varying some critical design parameter on the performance of the micro and nano-scale OFETs are addressed.

\subsection{Model validation}

For the sake of validation, the analytical model introduced in [33] is utilized. The pentacene based pchannel micro-scale ( $\mu$-OFET) is numerical and analytically modelled under two different channel lengths of $15 \mu \mathrm{m}$ and $30 \mu \mathrm{m}$, respectively (cf. figure 2). For $30 \mu \mathrm{m}$ OFET, experimental data, reported in [33], is also captured for numerical model accreditation. The drain and gate voltage were chosen in accordance with the seeded data from [33]. 
By observing the $30 \mu \mathrm{m}$ channel length OFET demonstrated in figure 2, a nearly typical matching between the analytical model and the numerical simulation is observed. While referring to the experimental data, the consistency is still detectable in the triode region, above $-6 \mathrm{~V}$ applied on the drain. In the saturation region, mismatching is observable in a decreasing trend while drain voltage increases. We attribute such mismatching to the hypothetical Ohmic contact assumed in the simulation model as well as the unidealistic organic material effects that are not addressed in the simulation model.

Another validation attempt is illustrated in figure 2, by reducing the channel length to reach $15 \mu \mathrm{m}$. Firstly, the matching between numerical and analytical models can still be observed. However, due to the nano-scale current (right vertical axis), the mismatching seems to be higher. In addition, comparing the 30 $\mu \mathrm{m}$ model to the $15 \mu \mathrm{m}$ model can highlight the impact of narrowing down the channel length in the pentacene OFETs. Herein, a three order of magnitude reduction in the drain current is recorded. This justifies the relatively long channel length used in the pentacene OFETs reported in the literature [41] with respect to those fabricated using polyaniline [37, 38]. A full polyaniline based OFET model is addressed in section 3.3. It is worth to mention that for the $15 \mu \mathrm{m}$ model, the drain voltage was forced not to exceed $-6 \mathrm{~V}$ with a gate voltage of $-2 \mathrm{~V}$ to avoid device break-down (simulation model boundaries).

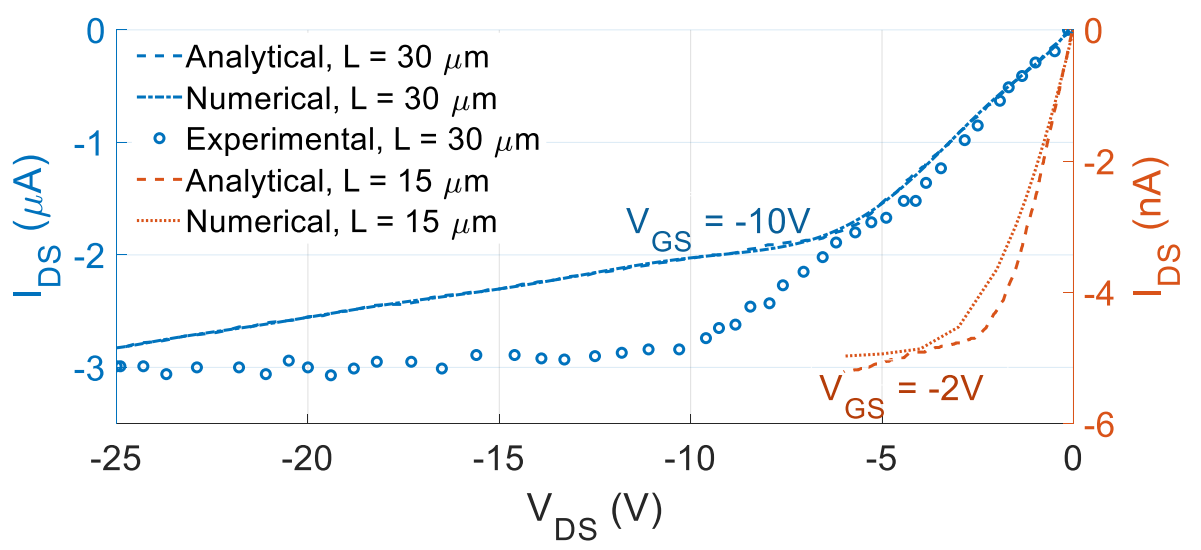

Fig. 2: $\mathrm{I}_{\mathrm{DS}}-\mathrm{V}_{\mathrm{DS}}$ using analytical, as well as numerical simulation model with respect to experimental data captured from [33] for pentacene based $\mu$-OFET at $15 \mu \mathrm{m}$ and $30 \mu \mathrm{m}$ channel lengths.

\section{2. $\mu$-OFET model}

Herein, the micro-scale OFET structure is numerically simulated with pentacene as an active OSC layer. As mentioned earlier in the introduction, p-channel OFETs are recommended due to the higher mobility of holes comparing to electrons in OSCs (cf. table 1). Initially, the $\mu$-OFET has been simulated with a fixed doping level as well as channel length and oxide thickness, following the model described in section 2 (see table 3). The $I_{D S}-V_{G S}$, and the $I_{D S}-V_{D S}$ characteristic curves for the standard $\mu$-OFET are plotted in figure 3. From figure 3-a, a positive threshold voltage is recorded, where we attribute this to low gate voltage with respect to the applied drain voltage, as reported in [43]. Additionally, the doping level has a significant contribution in adjusting the threshold voltage as discussed later in this section.

Secondly, the impact of the dielectric layer thickness of the pentacene OFET is studied and demonstrated in figure 4. Both $I_{D S^{-}} V_{G S}$, and $I_{D S^{-}} V_{D S}$ characteristics are simulated under fixed p-type doping and channel length (see table 3). As observed in figure 4-a, the threshold voltage showed negative trend while increasing the dielectric layer thickness, as a common behavior in FETs. Alternatively, figure 4-b concludes that the impact of the dielectric layer thickness variation on the drain current for a fixed gate voltage is minimum. 
Table 3: Performance characteristics for pentacene OFET in-terms of $\mathrm{V}_{\text {th }}, \mathrm{I}_{\mathrm{on} / \mathrm{off}}$, $\mathrm{SS}$ and field effect mobility under various oxide layer thickness and doping level.

\begin{tabular}{|c|c|c|}
\hline $\begin{array}{l}\text { OSC p-type doping }\left(\mathrm{N}_{\mathrm{a}}\right) \mathrm{cm}^{-3} / \text { Dielectric } \\
\text { thickness }(\mathrm{nm})\end{array}$ & Chrematistics & $\mu$-OFET \\
\hline \multirow{5}{*}{$10^{16} \mathrm{~cm}^{-3} / 200 \mathrm{~nm}$} & $\mathrm{~V}_{\text {th }}$ & $0.2 \mathrm{~V}$ \\
\hline & $\mathrm{I}_{\mathrm{on} / \mathrm{off}}$ & $1.3 \times 10^{11}$ \\
\hline & SS & $-0.06 \mathrm{~V} / \mathrm{dec}$ \\
\hline & $\mu_{\text {lin }}$ & $4.16 \times 10^{-3} \mathrm{~cm}^{2} / \mathrm{Vs}$ \\
\hline & $\mu_{\mathrm{sat}}$ & $4.57 \times 10^{-3} \mathrm{~cm}^{2} / \mathrm{Vs}$ \\
\hline \multirow{5}{*}{$10^{16} \mathrm{~cm}^{-3} / 250 \mathrm{~nm}$} & $\mathrm{~V}_{\text {th }}$ & $0.4 \mathrm{~V}$ \\
\hline & $\mathrm{I}_{\mathrm{on} / \mathrm{off}}$ & $1.72 \times 10^{11}$ \\
\hline & SS & $-1.37 \mathrm{~V} / \mathrm{dec}$ \\
\hline & $\mu_{\text {lin }}$ & $5.66 \times 10^{-3} \mathrm{~cm}^{2} / \mathrm{Vs}$ \\
\hline & $\mu_{\mathrm{sat}}$ & $6.7 \times 10^{-3} \mathrm{~cm}^{2} / \mathrm{Vs}$ \\
\hline \multirow{5}{*}{$10^{15} \mathrm{~cm}^{-3} / 200 \mathrm{~nm}$} & $\mathrm{~V}_{\mathrm{th}}$ & $-1.2 \mathrm{~V}$ \\
\hline & $\mathrm{I}_{\mathrm{on} / \mathrm{off}}$ & $1.72 \times 10^{10}$ \\
\hline & SS & $-0.67 \mathrm{~V} / \mathrm{dec}$ \\
\hline & $\mu_{\text {lin }}$ & $9.7 \times 10^{-4} \mathrm{~cm}^{2} / \mathrm{Vs}$ \\
\hline & $\mu_{\mathrm{sat}}$ & $1.8 \times 10^{-4} \mathrm{~cm}^{2} / \mathrm{Vs}$ \\
\hline
\end{tabular}

In order to study the performance variation in OFETs with varying the dielectric layer thickness, all output simulation parameters are listed in table 3. Herein, we select the threshold voltage $\left(\mathrm{V}_{\mathrm{th}}\right)$, the on/off current ratio, the sub threshold swing (SS), and the field effect mobility for saturation and linear regions $\left(\mu_{\mathrm{sat}}, \mu_{\mathrm{lin}}\right)$ as the output parameters to evaluate the OFET performance. For low threshold voltage applications, such as bio-sensing, lower dielectric layer thickness is recommended. However, such reduction in the layer thickness will be associated with a reduction in on/off current ratio as well as FET mobility's in both region of operation.

Another critical parameter is the active layer doping, addressed in figure 5. The simulation results highlight the significant impact of doping on adjusting the OFET characteristics. This agrees with the recently reported data in the literature in [44]. In terms of threshold voltage, figure 5-a demonstrates the capability of shifting the threshold voltage to the negative region by tuning the doping level. Additionally, the doping level can influence the drain current significantly as observed in figure 5-b. Again, by visiting table 3, a quantitative analysis in terms of the main output five parameters of OFET can be addressed. As observed from the recorded outputs, threshold voltage is inversely influenced by the doping level. Alternatively, the on/off current ratio shows a better performance with the rising of the doping level. Similarly, the field effect mobility increases with the increase of doping level, indicating an improved performance in OFET. 

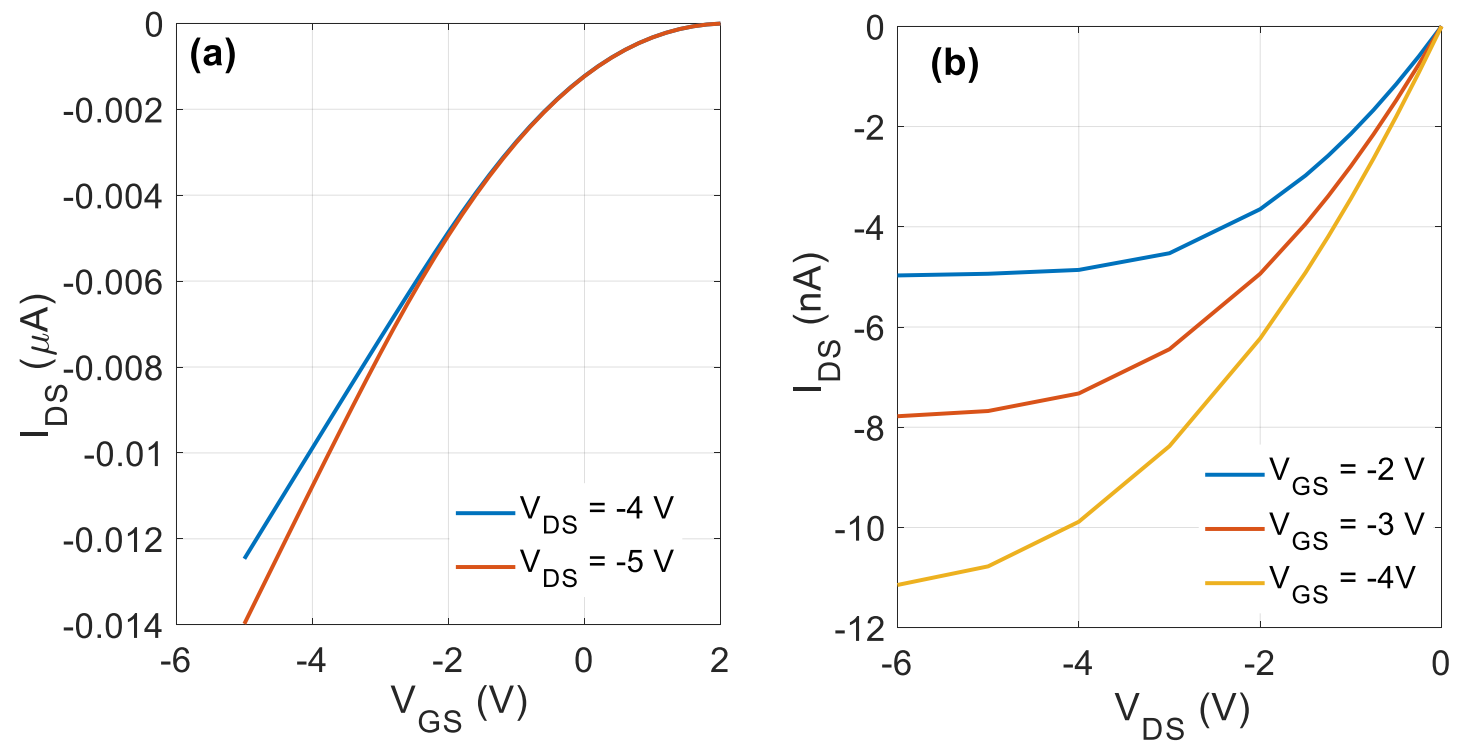

Fig. 3: The $\mathrm{I}_{\mathrm{GS}}-\mathrm{V}_{\mathrm{DS}}$, and the $\mathrm{I}_{\mathrm{DS}}-\mathrm{V}_{\mathrm{DS}}$ characteristic curves for the standard $\mu$-OFET.
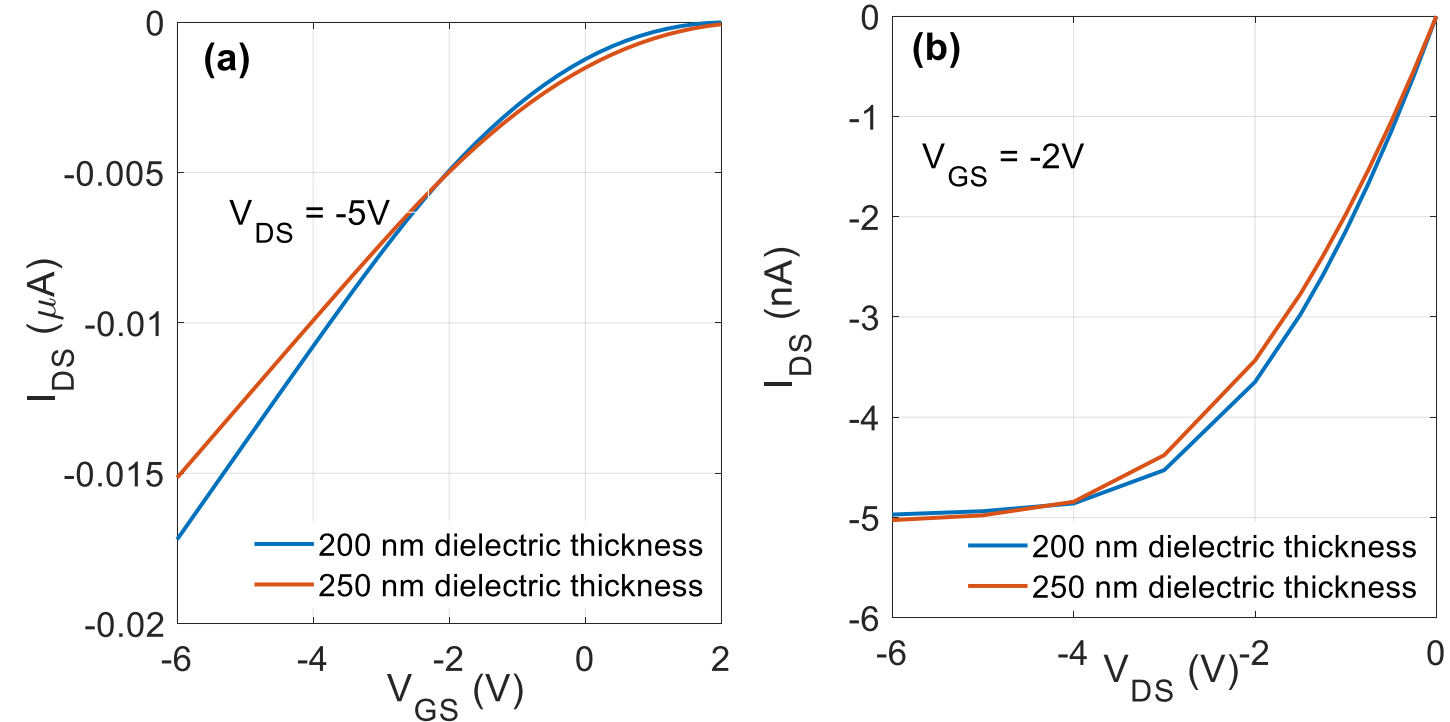

Fig. 4: The $I_{G S}-V_{D S}$, and the $I_{D S}-V_{D S}$ characteristic curves for the $\mu$-OFET under various dielectric layer thicknesses of $200 \mathrm{~nm}$ and $250 \mathrm{~nm}$, respectively. 

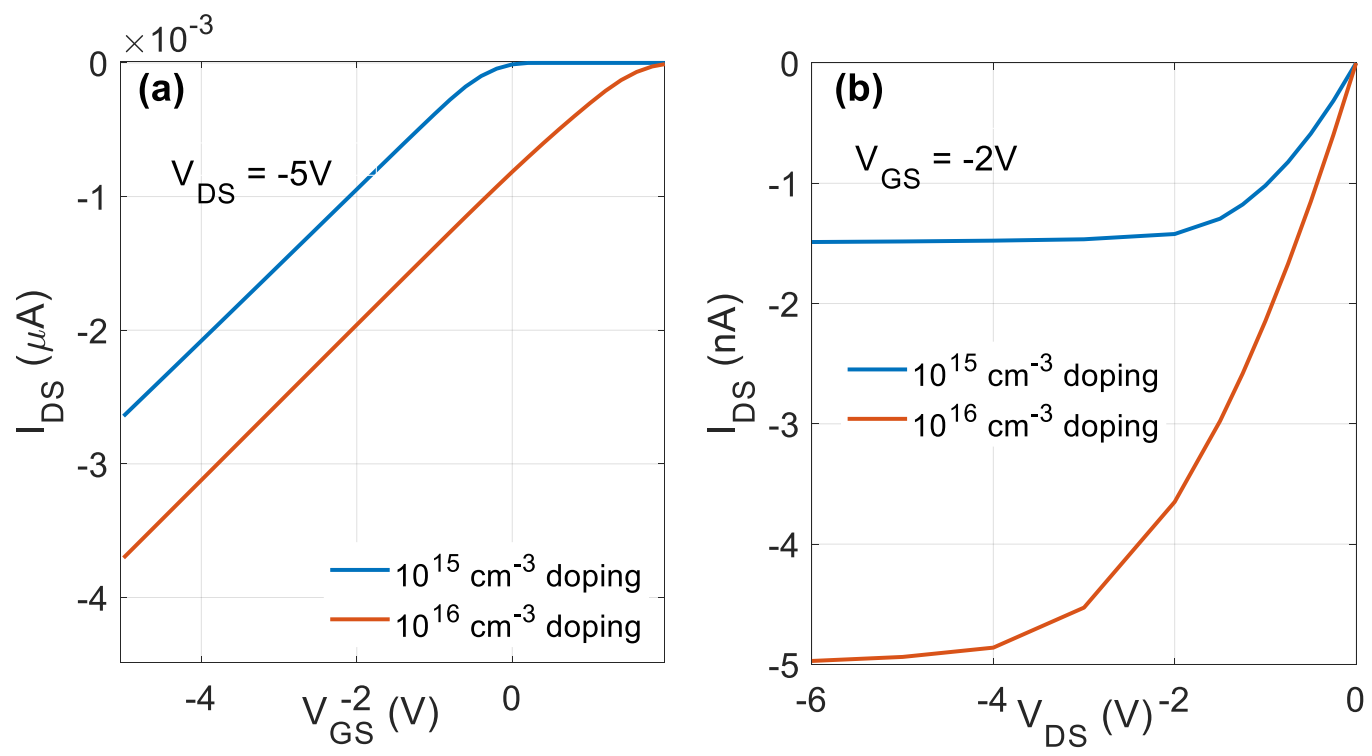

Fig 5: The $I_{G S}-V_{D S}$, and the $I_{D S}-V_{D S}$ characteristic curves for the $\mu$-OFET under various OSC active layer doping level of $10^{15} \mathrm{~cm}^{-3}$ and $10^{16} \mathrm{~cm}^{-3}$, respectively.

\section{3. n-OFET model}

Following the same procedure applied in section 3.2, p-doped polyaniline-based n-OFET is numerically investigated in this section. The characteristics $I_{D S}-V_{G S}$, and $I_{D S}-V_{D S}$ are analyzed based on the seeded material parameters listed in table 1. Applying all the initial parameters (see table 4), the standard characteristics for the n-OFET are plotted in figure 6 . A recognizable variation in the threshold voltage is observed while varying the voltage applied on the drain (cf. figure 6-a). This can be attributed to the ultrashort channel length $(30 \mathrm{~nm})$ with respect to the $\mu$-FET model, where drain voltage contribution was nearly neglected. Another significant observation is the enhancement of the drain current to be in microampere scale while in the pentacene model nano-ampere range current was detected. This justifies the booming trend of utilizing polyaniline as OSC material, due to its enhanced conductivity [45-47].

The impact of ranging the OFET channel length is studied through our work by analysing the current characteristics of polyaniline-based organic FET under $20 \mathrm{~nm}$ and $30 \mathrm{~nm}$, while fixing all other input parameters as mentioned earlier (see figure 7, and table 4). Results demonstrated an inverse relation between the threshold voltage and the channel length. Additionally, the channel length of the OFET influences the output resistance at the saturation region (cf. figure 7-b). Table 4 list the n-OFET performance evaluating parameters. An overall reduction is detected while reducing the channel length of the n-OFET. This typically agrees with the reported data in the literature [7, 13, 24, 25, 33], corresponds to the short channel length effect. However, a trade-off between sub threshold swing and the other evaluating parameters starts to appear. Such trade-off was previously reported in literature for other inorganic FET, as in [48].

The effect of active layer thickness is also investigated through this study (see table 4). The active layer thickness has demonstrated no recognizable effect on the threshold voltage, for $20 \mathrm{~nm}, 25 \mathrm{~nm}$ and $30 \mathrm{~nm}$ thicknesses. The output resistance in the saturation region slightly changes with the change in the active layer. Moreover, the impact of tuning the dielectric thickness on the threshold voltage and the drain current are highlighted in figure 8 . We noticed that the threshold voltage is inversely affected by the dielectric thickness, while the current decreases with the increase of dielectric thickness as shown in figure 8-b. With referring to the output parameters listed in table 4, on/off current ratio and field effect mobility are negatively impacted with the increase in the dielectric thickness. However, the sub-threshold 
swing has a better performance with this rising. Again, the same trade-off between the sub-threshold swing and the on/off current ratio as well as mobilities is observed.

Finally, the impact of p-doping level on the characteristic performance of n-OFETs is investigated through figure 9. The current characteristics for polyaniline based OFET simulated a decreasing threshold with the increase in doping levels. As reported in the pentacene micro-scale OFET, the doping level is classified as the most critical parameter in controlling both the threshold voltage and the drain current (cf. figure 9). Additionally, the trade-off between the on/off current ratio and field effect mobility, from one side, and the subthreshold swing, from the other side, is still recognizable (see table 4). The OFET reaches a saturation current up to $310 \mu \mathrm{A}$ with a threshold voltage of $+0.1 \mathrm{~V}$, under a p-type doping of $10^{17}$ $\mathrm{cm}^{-3}$.

Table 4: Performance characteristics for polyaniline n-OFET in-terms of $\mathrm{V}_{\mathrm{th}}, \mathrm{I}_{\mathrm{on} / \mathrm{off}}$, SS and field effect mobility under various channel lengths, active layer thicknesses, oxide layer thickness and doping level.

\begin{tabular}{|c|c|c|}
\hline $\begin{array}{c}\text { Channel length (nm)/ Active Layer } \\
\text { Thickness (nm)/ Dielectric Layer Thickness } \\
\text { (nm)/Doping Level }\left(\mathrm{cm}^{-3}\right)\end{array}$ & $\begin{array}{l}\text { Output } \\
\text { Chrematistic } \\
\text { parameters }\end{array}$ & $\mu$-OFET \\
\hline \multirow[t]{5}{*}{$30 \mathrm{~nm} / 20 \mathrm{~nm} / 30 \mathrm{~nm} / 10^{17} \mathrm{~cm}^{-3}$} & $\mathrm{~V}_{\mathrm{th}}$ & $0.2 \mathrm{~V}$ \\
\hline & $\mathrm{I}_{\mathrm{on} / \mathrm{off}}$ & $1.59 \times 10^{15}$ \\
\hline & SS & $-1.57 \mathrm{~V} / \mathrm{dec}$ \\
\hline & $\mu_{\text {lin }}$ & $4.05 \mathrm{~cm}^{2} / \mathrm{Vs}$ \\
\hline & $\mu_{\mathrm{sat}}$ & $1.7 \mathrm{~cm}^{2} / \mathrm{Vs}$ \\
\hline \multirow[t]{5}{*}{$20 \mathrm{~nm} / 20 \mathrm{~nm} / 30 \mathrm{~nm} / 10^{17} \mathrm{~cm}^{-3}$} & $\mathrm{~V}_{\text {th }}$ & $0.4 \mathrm{~V}$ \\
\hline & $\mathrm{I}_{\mathrm{on} / \mathrm{off}}$ & $8.8 \times 10^{14}$ \\
\hline & SS & $-3.6 \mathrm{~V} / \mathrm{dec}$ \\
\hline & $\mu_{\text {lin }}$ & $3.9 \mathrm{~cm}^{2} / \mathrm{Vs}$ \\
\hline & $\mu_{\mathrm{sat}}$ & $1.5 \mathrm{~cm}^{2} / \mathrm{Vs}$ \\
\hline \multirow[t]{5}{*}{$30 \mathrm{~nm} / 30 \mathrm{~nm} / 30 \mathrm{~nm} / 10^{17} \mathrm{~cm}^{-3}$} & $\mathrm{~V}_{\text {th }}$ & $0.4 \mathrm{~V}$ \\
\hline & $\mathrm{I}_{\mathrm{on} / \mathrm{off}}$ & $1.56 \times 10^{15}$ \\
\hline & SS & $-1.2 \mathrm{~V} / \mathrm{dec}$ \\
\hline & $\mu_{\text {lin }}$ & $4.3 \mathrm{~cm}^{2} / \mathrm{Vs}$ \\
\hline & $\mu_{\mathrm{sat}}$ & $2.5 \mathrm{~cm}^{2} / \mathrm{Vs}$ \\
\hline \multirow[t]{5}{*}{$30 \mathrm{~nm} / 20 \mathrm{~nm} / 50 \mathrm{~nm} / 10^{17} \mathrm{~cm}^{-3}$} & $\mathrm{~V}_{\text {th }}$ & $-0.4 \mathrm{~V}$ \\
\hline & $\mathrm{I}_{\mathrm{on} / \mathrm{off}}$ & $1.59 \times 10^{15}$ \\
\hline & SS & $-1.57 \mathrm{~V} / \mathrm{dec}$ \\
\hline & $\mu_{\operatorname{lin}}$ & $4.05 \mathrm{~cm}^{2} / \mathrm{Vs}$ \\
\hline & $\mu_{\text {sat }}$ & $1.7 \mathrm{~cm}^{2} / \mathrm{Vs}$ \\
\hline \multirow{5}{*}{$30 \mathrm{~nm} / 20 \mathrm{~nm} / 50 \mathrm{~nm} / 10^{15} \mathrm{~cm}^{-3}$} & $\mathrm{~V}_{\mathrm{th}}$ & $-0.1 \mathrm{~V}$ \\
\hline & $\mathrm{I}_{\mathrm{on} / \mathrm{off}}$ & $1.2 \times 10^{15}$ \\
\hline & SS & $-2.4 \mathrm{~V} / \mathrm{dec}$ \\
\hline & $\mu_{\text {lin }}$ & $27.7 \mathrm{~cm}^{2} / \mathrm{Vs}$ \\
\hline & $\mu_{\mathrm{sat}}$ & $8.4 \mathrm{~cm}^{2} / \mathrm{Vs}$ \\
\hline
\end{tabular}



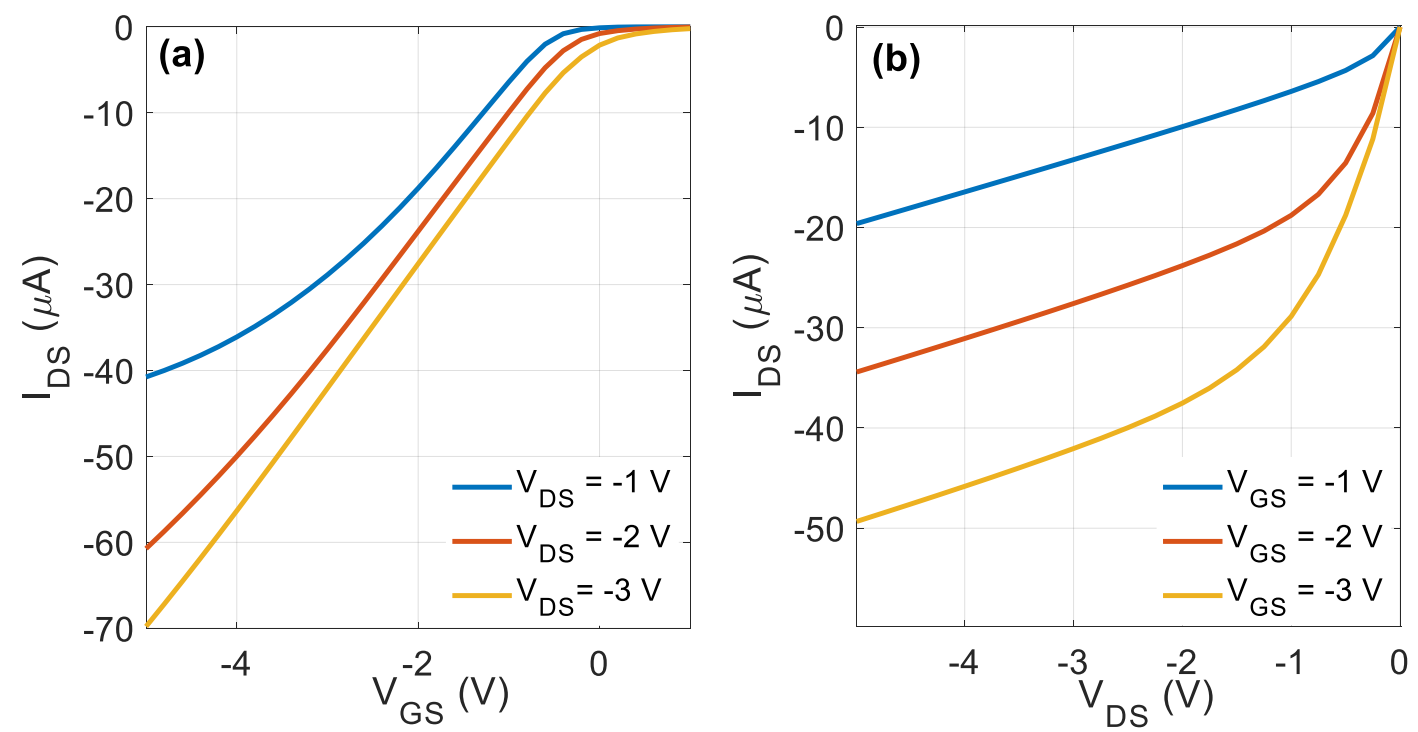

Fig. 6: The $\mathrm{I}_{\mathrm{GS}}-\mathrm{V}_{\mathrm{DS}}$, and the $\mathrm{I}_{\mathrm{DS}}-\mathrm{V}_{\mathrm{DS}}$ characteristic curves for standard polyaniline-based n-OFET.
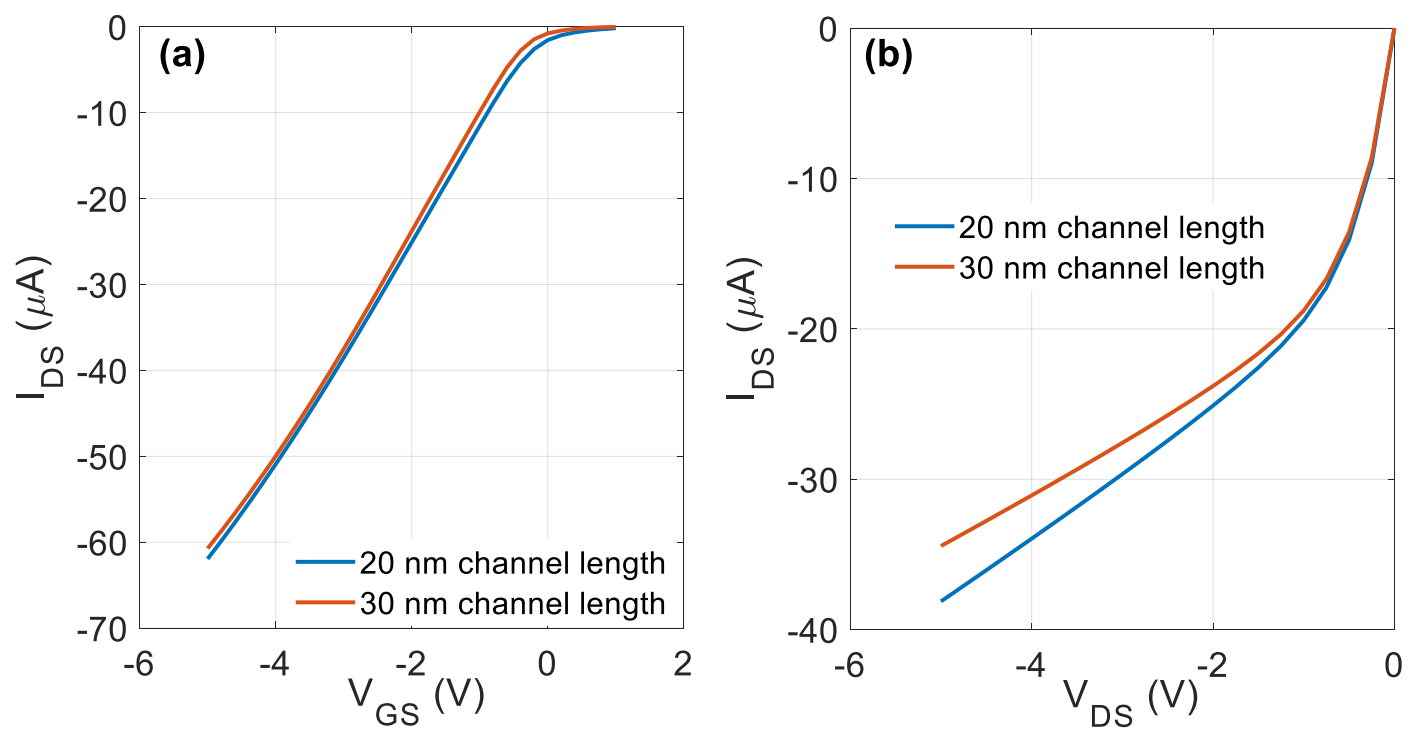

Fig. 7: The $\mathrm{I}_{\mathrm{GS}}-\mathrm{V}_{\mathrm{DS}}$, and the $\mathrm{I}_{\mathrm{DS}}-\mathrm{V}_{\mathrm{DS}}$ characteristic curves for polyaniline-based n-OFET under channel length of 20 $\mathrm{nm}$ and $30 \mathrm{~nm}$, respectively. 

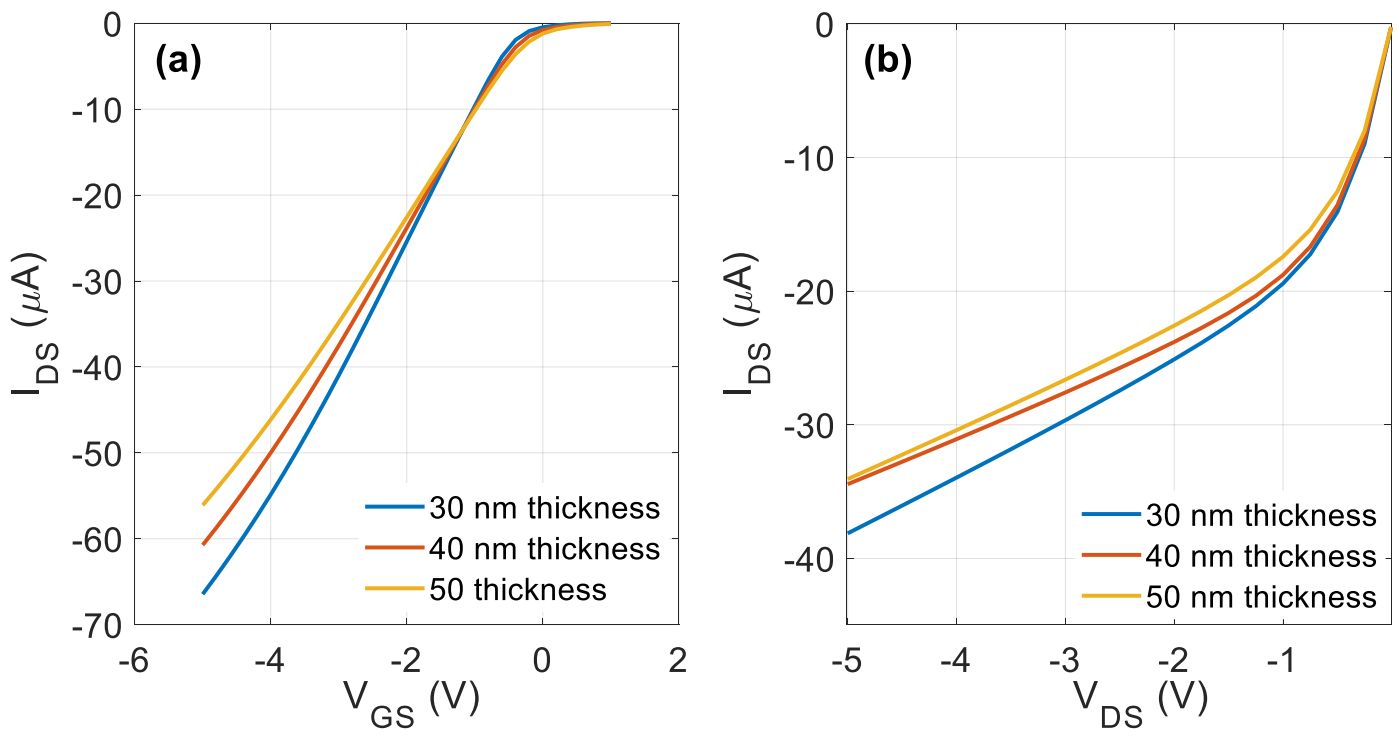

Fig. 8: The $I_{G S}-V_{D S}$, and the $I_{D S}-V_{D S}$ characteristic curves for polyaniline-based n-OFET under a set of dielectric layer thicknesses of $30 \mathrm{~nm}, 40 \mathrm{~nm}$ and $50 \mathrm{~nm}$, respectively.
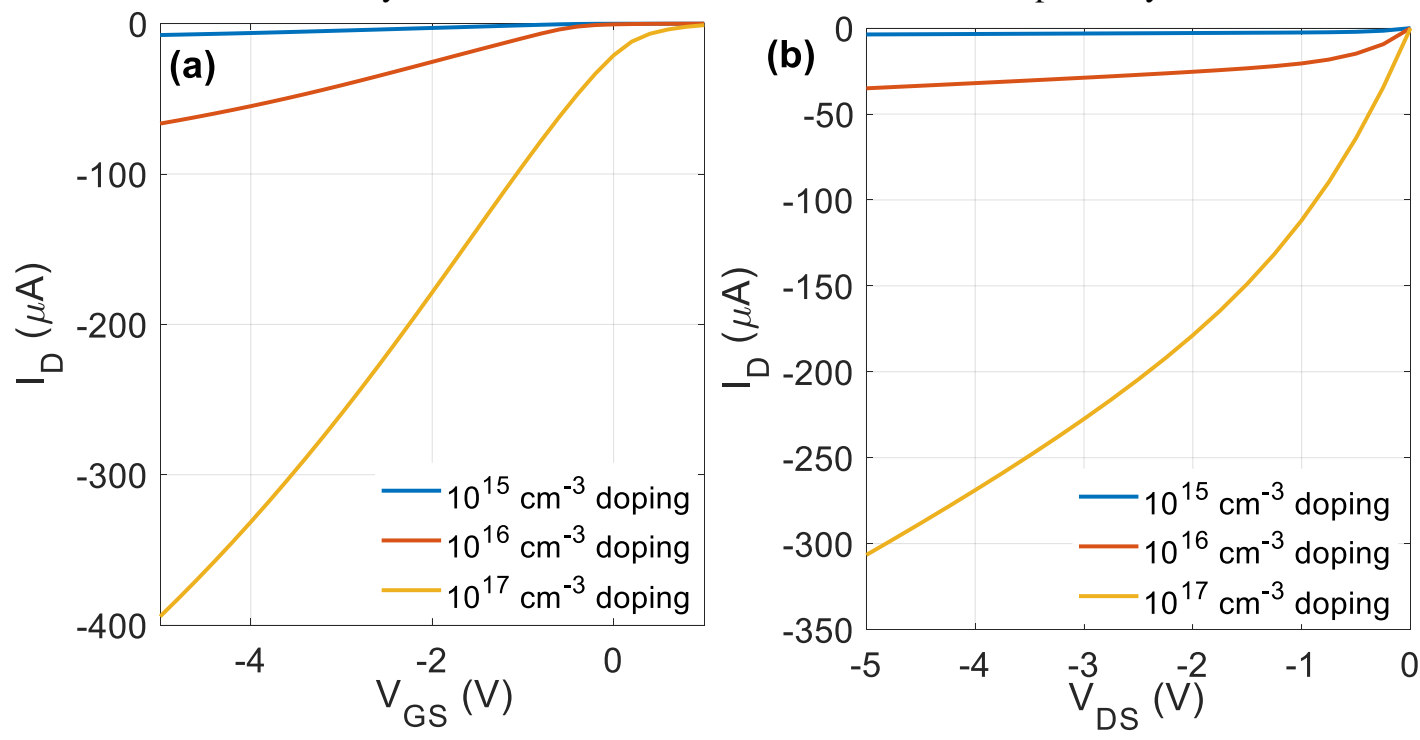

Fig. 9: The $\mathrm{I}_{\mathrm{GS}}-\mathrm{V}_{\mathrm{DS}}$, and the $\mathrm{I}_{\mathrm{DS}}-\mathrm{V}_{\mathrm{DS}}$ characteristic curves for polyaniline-based n-OFET under various p-type OSC active layer doping level including: $10^{15} \mathrm{~cm}^{-3}, 10^{16} \mathrm{~cm}^{-3}$, and $10^{17} \mathrm{~cm}^{-3}$, respectively.

\subsection{Pentacene against polyaniline n-OFET model}

As a terminating stage in the current study, the same nano-OFET model with $30 \mathrm{~nm}$ channel length is simulated while integrating polyaniline against pentacene as the main active layer. All parameters are kept the same to ensure fair comparison. The current-voltage OFET characteristics are simulated in Figure 10. Starting with figure 10-a, the pentacene model showed positively shifted threshold voltage while referring to polyalanine OFET. Besides that, the observed drain current for the polyalanine OFET is two orders of magnitude higher than that of pentacene. On the other hand, both organic semiconductor materials showed nearly the same behavior in the triode and the saturation regions.

Due to such low threshold voltage recorded in this paper (around $-0.1 \mathrm{~V}$ ), these devices are capable of being integrated in low-power micro/nano-meter range sensing application where low threshold voltage is 
recommended [44, 49, 50]. In addition, the demonstrated OFETs can be classified under low-power consumption transistors (micro-Watt power range). The full power consumption analysis for these transistors as well the parasitic capacitance associated is considered as a future extension to the current work.

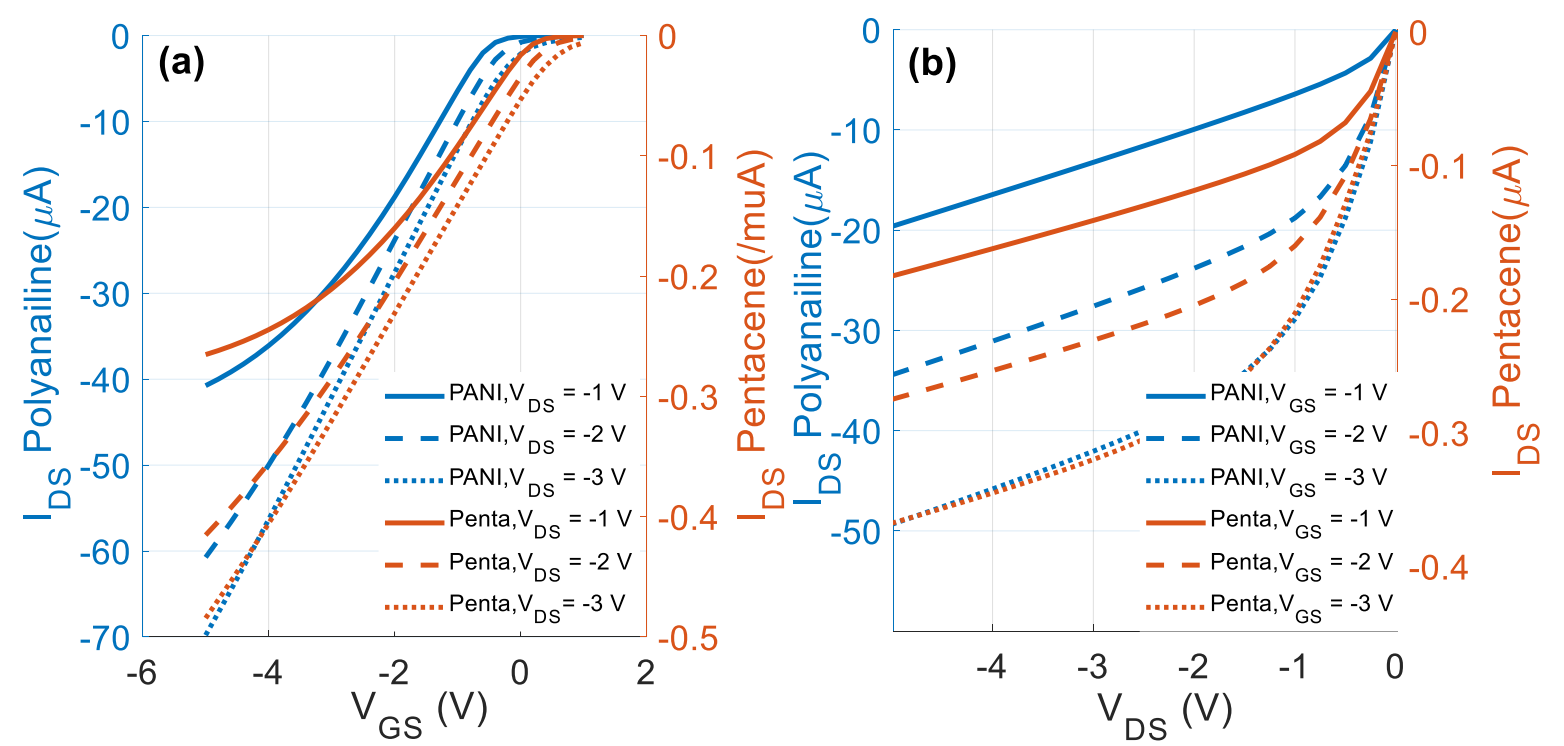

Fig. 10: The $I_{G S}-V_{D S}$, and the $I_{D S}-V_{D S}$ characteristic curves for polyaniline (PANI)-based against pentacene (Penta)based n-OFET.

\section{Conclusion}

Organic field effect transistors are ranked as one of the most potential devices in the field of organic electronics. Unfortunately, thermotical attempts in modelling the performance of these devices are rarely found in literature. Besides that, most of the reported models are limited to pentacene as an active organic semiconductor material. Herein, we present an attempt to model the I-V characteristic of OFETs using finite element method. The semiconductor module in Comsol Multiphysics is utilized in describing the carrier transport mechanisms in the OFETs.

As design parameters, the transistor dimensions, the dielectric layer thickness, and the doping injection level are considered in this study. On the other hand, the threshold voltage, the on/off current ratio, the subthreshold swing, and the field effect mobilities in the triode and saturation regions are treated as the main output characteristic parameters.

Principally, our numerical model has shown a perfect agreement with the analytical results, as well as acceptable mismatching with previously experimental data in the literature. The simulated outputs have shown the significance of the doping level in adjusting both the threshold voltage and drain current level, regardless the device dimension or the OSC material used. Moreover, a trade-off between the subthreshold swing, from one hand and the on/off current ratio along with the field effect mobility, from the other hand, was continuously observed in the nano-FET model.

Polyalanine reported an enhanced drain current, two orders of magnitude higher than the pentacene model, under $30 \mathrm{~nm}$ channel length. With the impact of doping adjustments, both polyalanine and pentacene have recorded a negative threshold voltage of -0.1 and $-1.2 \mathrm{~V}$, respectively. In this context, polyalanine can be promoted as an effective material in biosensing applications where low threshold voltage is more appropriate. 


\section{References}

[1] J Zhao, Z Xu, MK Law, et al. (2021) IEEE Access: 1. Doi:10.1109/ACCESS.2021.3050431

[2] A Gaiardo, D Novel, E Scattolo, et al. (2021) Sensors 21: 783.

[3] P-Y Kuo, Y-Y Chen (2021) IEEE Transactions on Instrumentation and Measurement 70: 1.

[4] A Bhattacharjee, K Kandpal (2021) 2021 IEEE Latin America Electron Devices Conference (LAEDC)IEEE,

[5] S Grigg, R Pullin, M Pearson, et al. (2021) Structural Control and Health Monitoring 28: e2701.

[6] T-T Bui, F Goubard, M Ibrahim-Ouali, D Gigmes, F Dumur (2018) Applied Sciences 8: 494.

[7] SG Surya, HN Raval, R Ahmad, P Sonar, KN Salama, VR Rao (2019) TrAC Trends in Analytical Chemistry 111: 27.

[8] YH Lee, M Jang, MY Lee, OY Kweon, JH Oh (2017) Chem 3: 724.

[9] M Song, J Seo, H Kim, Y Kim (2017) Scientific reports 7: 1.

[10] M Song, J Seo, H Kim, Y Kim (2017) ACS omega 2: 4065.

[11] OO Ogunleye, H Sakai, Y Ishii, H Murata (2019) Organic Electronics 75: 105431.

[12] C Sun, R Li, Y Song, et al. (2021) Analytical chemistry 93: 6188.

[13] T Minami, T Sato, T Minamiki, K Fukuda, D Kumaki, S Tokito (2015) Biosensors and Bioelectronics 74: 45.

[14] J Song, J Dailey, H Li, et al. (2018) Advanced Functional Materials 28: 1802605.

[15] A Świst, J Sołoducho (2012) CHEMIK nauka-technika-rynek 1: 289.

[16] C Chiang, C Fincher Jr, Y Park, et al. (1978) Physical Review Letters 40: 1472.

[17] BD Guenther, D Steel (2018) Encyclopedia of modern optics. Academic Press,

[18] RJ Martín-Palma, J Martínez-Duart (2017) Nanotechnology for Microelectronics and Photonics. Elsevier,

[19] M Kus, TY Alic, C Kirbiyik, C Baslak, K Kara, DA Kara (2018) Handbook of Nanomaterials for Industrial ApplicationsElsevier,

[20] B Kumar, BK Kaushik, YS Negi (2014) Polymer Reviews 54: 33.

[21] X Tao, V Koncar (2016) Smart Textiles and their ApplicationsElsevier,

[22] O Ostroverkhova (2018) Handbook of Organic Materials for Electronic and Photonic Devices. Woodhead Publishing,

[23] PT Liu (2018) Encyclopedia of Modern OpticsElsevier,

[24] W-Y Lee, J Mei, Z Bao (2016) THE WSPC REFERENCE ON ORGANIC ELECTRONICS: ORGANIC SEMICONDUCTORS: Fundamental Aspects of Materials and ApplicationsWorld Scientific,

[25] S Allard, M Forster, B Souharce, H Thiem, U Scherf (2008) Angewandte Chemie International Edition 47: 4070.

[26] I Kymissis, C Dimitrakopoulos, S Purushothaman (2001) IEEE Transactions on Electron Devices 48: 1060.

[27] ZA Lamport, HF Haneef, S Anand, M Waldrip, OD Jurchescu (2018) Journal of Applied Physics 124: 071101.

[28] O Jurchescu (2013) Conductivity measurements of organic materials using fieldeffect transistors (FETs) and space-charge-limited current (SCLC) technique. Woodhead Publishing,

[29] V Raghuwanshi, D Bharti, AK Mahato, I Varun, SP Tiwari (2019) ACS applied materials \& interfaces 11: 8357.

[30] Y Liu, J-Q Zhao, W-J Sun, et al. (2018) Chinese Journal of Polymer Science 36: 918.

[31] H Li, FS Kim, G Ren, SA Jenekhe (2013) Journal of the American Chemical Society 135: 14920.

[32] S Lan, Y Yan, H Yang, et al. (2019) Journal of Materials Chemistry C 7: 4543.

[33] I Benacer, Z Dibi (2014) International Journal of Advanced Science and Technology 66: 79.

[34] S Fatima, U Rafique, U Ahmed, M Ahmed (2019) Solid-State Electronics 152: 81. 
[35] Y Yang, RA Nawrocki, RM Voyles, HH Zhang (2021) Organic Electronics 88: 106000.

[36] S Cho, JS Lee, H Joo (2019) Polymers 11: 1965.

[37] K Amer, S Ebrahim, M Feteha, M Soliman, A El-Shaer (2017) 2017 34th National Radio Science Conference (NRSC)IEEE,

[38] M Mahadik, G Bodkhe, N Ingle, et al. (2021) Journal of Electronic Materials 50: 2339.

[39] S Nair, M Kathiresan, T Mukundan (2018) Semiconductor Science and Technology 33: 025006.

[40] H Wang, J Huang, S Xing, J Yu (2016) Organic Electronics 28: 11.

[41] G Gu, MG Kane, JE Doty, AH Firester (2005) Applied Physics Letters 87: 243512.

[42] A Pal, B Kumar, G Tripathi (2016) 2016 International Conference on Emerging Trends in Communication Technologies (ETCT)IEEE,

[43] B Kumar, BK Kaushik, YS Negi (2013) Journal of Vacuum Science \& Technology B, Nanotechnology and Microelectronics: Materials, Processing, Measurement, and Phenomena 31: 012401.

[44] I Lashkov, K Krechan, K Ortstein, et al. (2021) ACS Applied Materials \& Interfaces 13: 8664.

[45] H Wang, S-i Yi, X Pu, C Yu (2015) ACS applied materials \& interfaces 7: 9589.

[46] MA Moussa, AM Ghoneim, MH Abdel Rehim, SA Khairy, MA Soliman, GM Turky (2017) Journal of Applied Polymer Science 134: 45415.

[47] MG Hosseini, PY Sefidi, S Kinayyigit (2021) Materials Science in Semiconductor Processing 121: 105440.

[48] S Kim, S Go, S Kim (2021) Japanese Journal of Applied Physics 60: SCCE07.

[49] HR Yang, YY Lai (2021) Advanced Electronic Materials 7: 2000939.

[50] J-H Kim, JT Jang, J-H Bae, et al. (2021) Micromachines 12: 327. 